\title{
Nanostructure-Related Magnetic Properties of Various Mesoporous Cobalt Oxide and Cobalt Ferrite Spinel Phases
}

S. Haffer, T. Walther, R. Köferstein, S.G. Ebbinghaus, M. Tiemann

J. Phys. Chem. C, 117 (2013) 24471-24478

DOI: $10.1021 / \mathrm{jp} 409058 \mathrm{t}$

Nanostructure-related magnetic properties are investigated systematically for various mesoporous cobalt oxide $\left(\mathrm{Co}_{3} \mathrm{O}_{4}\right)$ and cobalt ferrite $\left(\mathrm{CoFe}_{2} \mathrm{O}_{4}\right)$ spinel phases. Synthesis of the materials by nanocasting offers the opportunity to obtain materials which are different from each other with respect to both specific surface area and crystallite size. As a result, the respective contributions of two types of interfaces, namely, "solid-gas" and "solid-solid" interfaces, to the magnetic ordering can be distinguished. Structural characterization of the porous materials by X-ray diffraction, $\mathrm{N}_{2}$ physisorption, and electron microscopy as well as investigation of the magnetic behavior (field-dependent magnetization and temperaturedependent susceptibility) are presented.

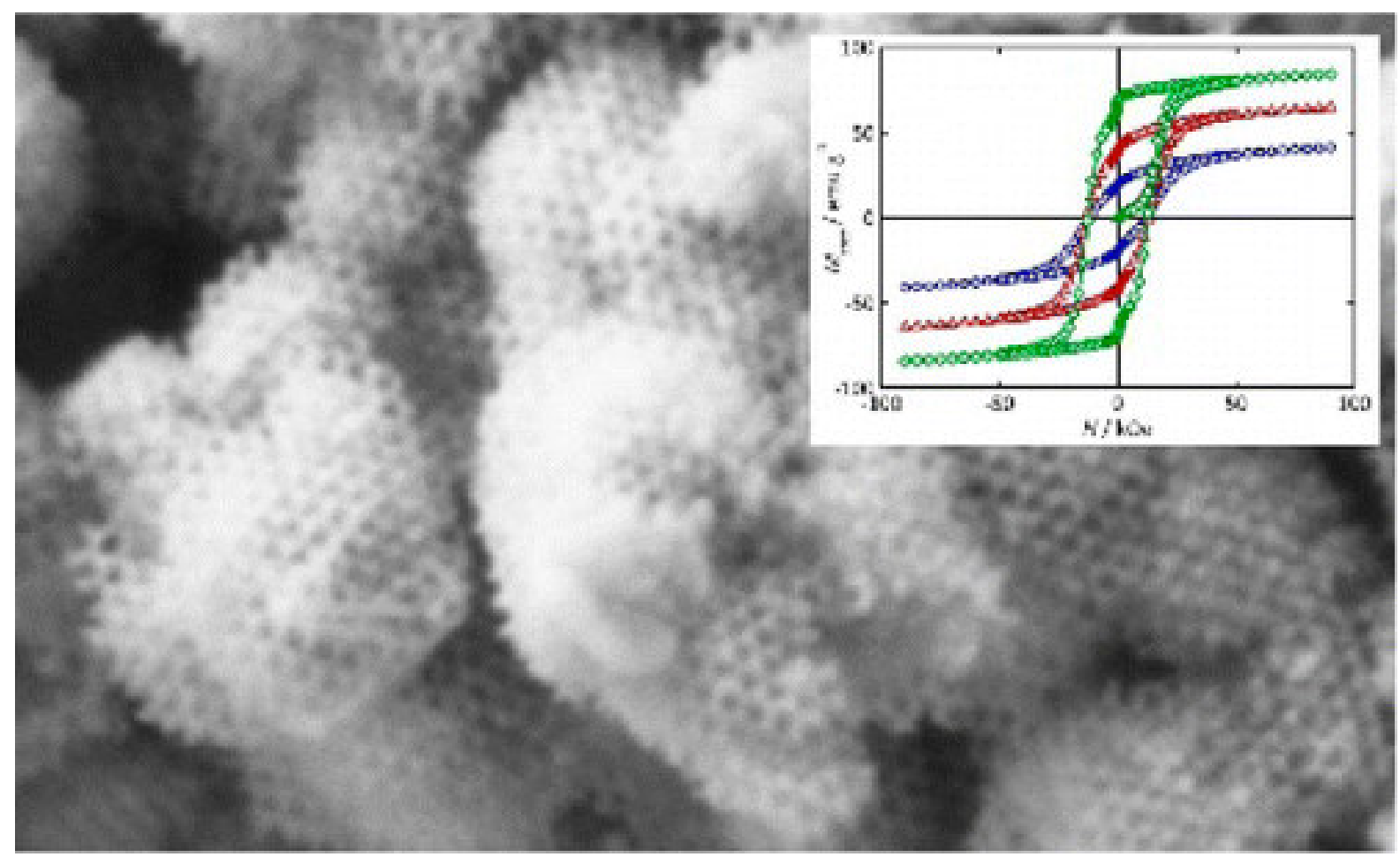

